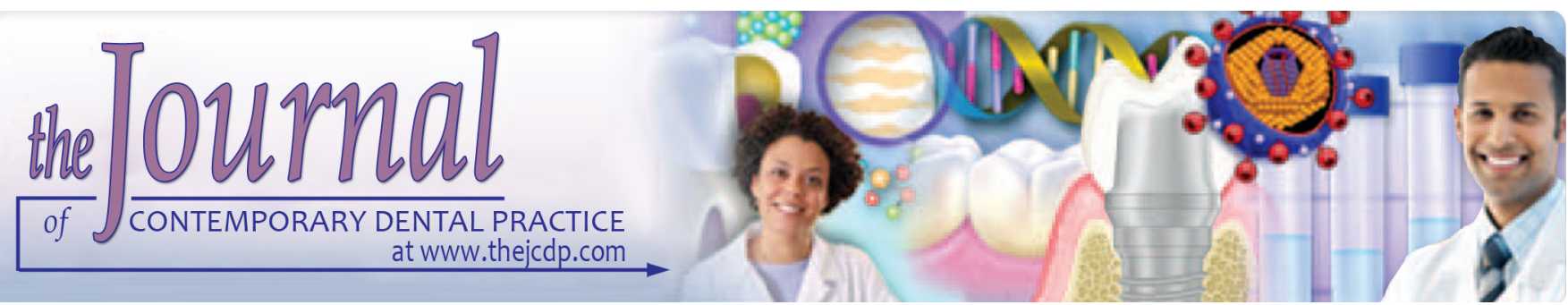

\title{
Twelve Impacted Supernumerary Teeth in a Nonsyndromic Patient: A Rare Case Report
}

${ }^{1}$ Ghassan M Al-Iryani, ${ }^{2}$ Fareedi Mukram Ali

\begin{abstract}
Teeth in excess number than the normal count are called supernumerary teeth. They can be either unilateral or bilateral and single or multiple, found at any place in the dental arch, but most commonly found in the anterior maxillary region. Supernumerary teeth are commonly associated with syndromes when present in more numbers, but can be idiopathic. The present study shows a case report of a 16-year-old female patient who reported with overretained deciduous teeth. A panoramic radiograph showed multiple impacted supernumerary teeth. Based on clinical features and radiographic examination, a diagnosis of idiopathic hyperdontia was given. In such types of patients, management must be planned by a multidisciplinary approach.
\end{abstract}

Keywords: Extra teeth, Impacted teeth, Supernumerary teeth.

How to cite the article: Al-Iryani GM, Ali FM. Twelve Impacted Supernumerary Teeth in a Nonsyndromic Patient: A Rare Case Report. J Contemp Dent Pract 2017;18(4):342-344.

Source of support: Nil

Conflict of interest: None

\section{INTRODUCTION}

Teeth arise through a series of interactions among neural crest-derived mesenchyme and the oral epithelium. ${ }^{1}$

Hyperdontia, or supernumerary teeth, is the presence of an excessive number of teeth in relation to the normal dental formula (20 in the deciduous dentition and 32 teeth in the permanent dentition). ${ }^{2}$

The prevalence is different for primary and permanent dentition in various populations and is 0.5 to $5.3 \%$ and 0.2 to $0.8 \%$ respectively. In permanent dentition,

1,2Department of Oral and Maxillofacial Surgery, College of Dentistry, Jazan University, Jazan, Kingdom of Saudi Arabia

Corresponding Author: Ghassan M Al-Iryani, Department of Oral and Maxillofacial Surgery, College of Dentistry, Jazan University, Jazan, Kingdom of Saudi Arabia, e-mail: faridi17@ rediffmail.com the prevalence of the supernumerary premolars ranges from 0.075 to $0.26 \%$, accounting for about $10 \%$ of all the supernumerary cases. ${ }^{3}$

Various terminologies used for this condition include hyperdontia; third dentition; polyphyodontism; duplicate teeth; aberrant, supplemental, and conoidal teeth; and hyperdontia. Hyperdontia is termed "real" when the number of teeth actual increases and "false" if the condition occurs because of delay in the shedding of deciduous teeth. ${ }^{3}$ Multiple hyperdontia refers to the presence of one or more supernumerary teeth in an individual. ${ }^{1}$

Multiple supernumerary teeth usually are syndromic. Such conditions are less common in patients without any associated diseases or syndromes. It has been reported that the prevalence of multiple supernumerary teeth in nonsyndromic patients is $>1 \%$. 1,4

\section{CASE REPORT}

A 16-year-old female patient reported with a complaint of missing teeth in the maxillary and mandibular anterior region. On clinical examination, overretained deciduous teeth were present in all four quadrants. Retained second deciduous molars and deciduous canines were present in all quadrants, while the first deciduous molars were retained only in the lower arch. In the upper incisor's area, the right central was the only tooth present. In the lower incisor's area, there were three partially erupted teeth. The patient's medical and family history and general physical clinical examination were noncontributory. No clinical manifestations of any syndromic abnormalities were detected. The patient gave a history of extractions in both upper and lower anterior segments through the previous 3 years in a rural dental clinic. She could not give an accurate count of the extracted teeth, nor could we retrieve any records. On radiographic examination, surprisingly, numerous impacted teeth were present in all four quadrants. We 


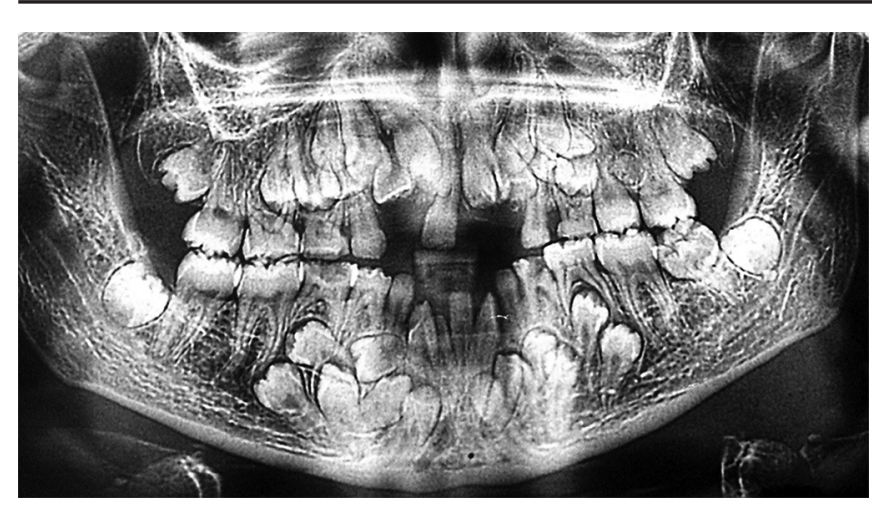

Fig. 1: Orthopantomograph of twelve impacted supernumerary teeth

could note two premolars and one canine were impacted in each quadrant, making it a total of 12 supernumerary teeth. In the upper and lower anterior segments, incisors were present but either fully or partially impacted, except for a fully erupted upper right central. The patient, due to social customs, refused us the permission to obtain clinical photographs. The impacted supernumerary teeth showed various angulations (Fig. 1). The patient was planned for a cone beam computed tomography (CBCT) and referral to an orthodontist for consultation. The necessity for surgical intervention was discussed with the patient and her parents, but they were not keen to go for any surgical procedures. They defaulted their consultation appointment with the orthodontist and refused to reschedule.

\section{DISCUSSION}

Supernumerary teeth can occur unilaterally, singly, bilaterally, or multiply and in one or both jaws. They occur more commonly among males. ${ }^{5}$

Primosh $^{6}$ classified the presence of supernumerary teeth according to their shape as follows:

- Supplemental/eumorphic: It is actual duplication of the normal dental count series. The most common supplementary teeth are permanent maxillary lateral incisors, bicuspids, and molars. This is also called as incisorformism.

- Rudimentary/dysmorphic: These are supernumerary teeth that have abnormal shape or size. These are smaller in size and can be:

- Conical

- Molar shaped

- Tubercular.

The most common supernumerary teeth are maxilla midline supernumeraries, maxillary fourth molars, maxillary paramolars, mandibular premolars, maxillary lateral incisors, mandibular fourth molars, and maxillary premolars, in the order of frequency. ${ }^{5}$
More than 20 syndromes or other developmental conditions were found to be associated with the presence of supernumerary teeth. ${ }^{5}$

Supernumerary teeth can be associated with numerous syndromes; the most common are craniofacial dysostosis, cleidocranial dysplasia, cleft lip and palate, Down's syndrome, and Gardner syndrome. ${ }^{6}$ Such syndromes associated with supernumerary teeth have apparent clinical features and usually are detectable by clinical examination.

For the explanation of the etiology of the supernumerary teeth, various theories have been put forward:6,7

- Phylogenetic theory: It represents analogous to the anthropoids having greater number of teeth in the dental setup

- Dental lamina hyperactivity theory: This most accepted theory states that extra teeth are formed as a result of alterations of dental lamina hyperactivity at the initial stage of development of dentition

- Dental follicle dichotomy theory: According to this theory, the follicle is divided into two equal or different parts leading to one dysmorphic and one similar tooth or two similar teeth

- Genetic factors: Supernumerary teeth can be associated with a dominant, autosomal, recessive gene. The importance of heredity is supported by the increased number of supernumerary teeth in relatives of those affected. ${ }^{6,7}$

Most of the extra teeth can be presented with one or more of the following complications: ${ }^{8}$

- Crowding

- Delay or prevention of eruption of associated permanent teeth

- Rotation or displacement of permanent teeth

- Incomplete space closure when doing orthodontic treatment

- Dilacerations or abnormal root development of the permanent teeth associated

- Adjacent teeth root resorption

- Supernumerary teeth forming late.

Although multiple extra teeth in nonsyndromic patients are rare, their presence can create various clinical problems. Therefore, suitable management after a thorough clinical and radiographic examination is must. ${ }^{5}$

Rajab and Hamdan ${ }^{9}$ in their survey of 152 child cases in a Jordanian population, found that $90 \%$ of the extra teeth were in the premaxilla area and while $77 \%$ of the subjects had just one supernumerary, $18.4 \%$ had two, and $4.6 \%$ had three or more supernumerary teeth.

The present case was one of the rarest reported cases with the presence of 12 supernumerary teeth. Review of the literature showed only a few reported cases of nonsyndromic multiple supernumerary teeth. Sivapathasundharam and Einstein ${ }^{10}$ reported 12 impacted 
supernumerary teeth similar to premolars in a 20-yearold male.

Krishnan et $\mathrm{al}^{11}$ reported the presence of 11 supernumerary teeth, while Srivatsan and Aravindha $\mathrm{Babu}^{12}$ reported the occurrence of 10 supernumerary teeth. Previous studies have shown that in nonsyndromic patients, the mandibular premolar area was the most common site. ${ }^{13}$

Solares and Romero ${ }^{14}$ found that $74 \%$ of supernumerary teeth were located in the mandibular premolar region. However, in our present case, supernumerary teeth were found in both the right and left premolar and the canine region of both maxilla and mandible.

It was also reported in the previous literature that Asians were more affected with supernumerary teeth than others. The present case is from Yemen.

The development of CBCT can provide threedimensional (3D) volumetric image construction of dental and nearby maxillofacial anatomical structures along with high-dimensional accuracy and isotropic resolution. Thus, 3D imaging systems have provided dental practitioners to visualize supernumerary teeth having more details and better contrast. 8,15

\section{CONCLUSION}

Extra teeth are less common but can lead to numerous complications. The dentist should recognize the signs as early as possible, particularly those that can cause problems or complications in eruption as seen in the presented case, and should perform proper investigations and treatment.

\section{REFERENCES}

1. Thumati P, David CM, Tiwari R. Non-syndromic multiple supernumerary teeth: a case report and review of literature. IJSS Case Rep Rev 2014 Oct;1(5):1-5.

2. Yagüe-García J, Berini-Aytés L, Gay-Escoda C. Multiple supernumerary teeth not associated with complex syndromes: a retrospective study. Med Oral Patol Oral Cir Bucal 2009 Jul;14(7):E331-E336.

3. Saluja KS, Singh B, Bhatia TK. An atypical case of nonsyndromic multiple impacted supernumerary teeth - a case report. Int J Contemp Med Res 2016 May;3(5):1423-1425.

4. Sood PB, Patil B, Godhi S, Shetty DC. Multiple supernumerary teeth and odontoma in the maxilla: a case report. Contemp Clin Dent 2010 Jan-Mar;1(1):45-46.

5. Orhan AI, Ozer L, Orhan K. Familial occurrence of nonsyndromal multiple supernumerary teeth. A rare condition. Angle Orthod 2006 Sep;76(5):891-897.

6. Primosh R. Anterior supernumerary teeth assessment and surgical intervention in children. Pediatr Dent 1981;3:204-215.

7. Khambete N, Kumar R. Genetics and presence of non-syndromic supernumerary teeth: a mystery case report and review of literature. Contemp Clin Dent 2012 Oct-Dec;3(4):499-502.

8. David Ditto S, Akhila R. Management of multiple impacted supernumerary teeth in a non-syndromic patient using cone beam CT. Dentistry 2014;4:190.

9. Rajab LD, Hamdan MA. Supernumerary teeth: review of the literature and a survey of 152 cases. Int J Paediatr Dent 2002 Jul;12(4):244-254.

10. Sivapathasundharam B, Einstein A. Non-syndromic multiple supernumerary teeth: report of a case with 14 supplemental teeth. Indian J Dent Res 2007 Jul-Sep;18(3):144.

11. Krishnan B, Narasimhan B, Nirupama C. Nonsyndromic multiple supernumerary teeth: a case report of 11 supernumerary teeth. J Indian Acad Oral Med Radiol 2012 Oct-Dec;24(4): 296-299.

12. Srivatsan $P$, Aravindha Babu N. Mesiodens with an unusual morphology and multiple impacted supernumerary teeth in a non-syndromic patient. Indian J Dent Res 2007 Feb;18(3): 138-140.

13. Acikgoz A, Acikgoz G, Tunga U, Otan F. Characteristic and prevalence of non-syndromic multiple supernumerary teeth: a retrospective study. Dentomaxillofac Radiol 2006 May;35(3):185-190.

14. Solares R, Romero MI. Supernumerary premolars: a literature review. Pediatr Dent 2004 Sep-Oct;26(5):450-458.

15. Roopa KB, Poornima P, Pathak S, Neena IE. Bilateral supernumerary cusps on deciduous and permanent molars: a case report with a short review. Int J Contemp Dent Med Rev 2015;2015:1-3. 